\title{
Marcelo Milano Vieira e a disciplina Administração Brasileira
}

\author{
Marcelo Milano Vieira and the discipline Brazilian Administration
}

Paulo Emílio Matos Martins ${ }^{1}$

Leonardo Vasconcelos Cavalier Darbilly ${ }^{2}$

Diana Costa de Castro $^{3}$

\section{Palavras Prévias}

O registro que se segue é uma homenagem à memória do professor Marcelo Milano Falcão Vieira, falecido recentemente, e uma forma de reiterar a admiração e a amizade que a ele devotamos ao longo do tempo em que juntos convivemos na Escola Brasileira de Administração Pública e de Empresas da Fundação Getulio Vargas no Rio de Janeiro.

Sem dúvida, discorrer sobre a rica contribuição de Marcelo Milano para a área da Administração não é tarefa fácil, tendo em vista a qualidade e a quantidade de trabalhos que ele produziu em sua trajetória acadêmica, quer durante o período em que foi professor na Escola Brasileira de Administração Pública e de Empresas da Fundação Getulio Vargas, como também ao longo de seu percurso como docente na Universidade Federal de Pernambuco (UFPE) e na Universidade Federal do Rio Grande do Sul (UFRGS).

Assim, registraremos a seguir, em breves notas, a contribuição dada pelo saudoso homenageado à difusão da ideia de construção da disciplina Administração Brasileira; sua preocupação com a hegemonia das teorias estrangeiras no pensamento sobre Administração; a importância que via na utilização dos autores brasileiros que pensaram o contexto nacional na análise das nossas organizações; e, por fim, sua incansável defesa do pensamento crítico nos estudos organizacionais. Para isso, abordaremos o seu pensamento e a sua relação com os grupos de pesquisa: Programa de Estudos de Administração Brasileira (ABRAS) e Observatório da Realidade Organizacional.

Diferentemente de outras disciplinas sociais, a Administração, tendo por base seus primeiros tratados (FAYOL, 1950 [1 $1^{\mathrm{a}}$ ed.1916] e TAYLOR, 1970 [1 $1^{\mathrm{a}}$ ed.1911]), vem construindo o seu corpus teórico com foco

Artigo submetido em 07 de fevereiro de 2012 e aceito para publicação em 07 de março de 2012.

1 Doutor em Administração pela Fundação Getulio Vargas/EAESP; Professor titular e Coordenador do Programa de Estudos de Administração Brasileira (ABRAS) da Fundação Getúlio Vargas. Endereço: FGV/EBAPE - Escola Brasileira de Administração Pública e de Empresas, Praia de Botafogo, 190 - $4^{\circ}$ e $5^{\circ}$ andares, Botafogo, CEP 22250-900, Rio de Janeiro - RJ, Brasil. E-mail: pemiliom@fgv.br

2 Doutorando da Fundação Getulio Vargas/EBAPE, sob orientação do Prof. Marcelo Milano F. Vieira até seu falecimento; Integrante do grupo de pesquisa Observatório da Realidade Organizacional, núcleo Rio de Janeiro; Professor da Universidade Federal Rural do Rio de Janeiro/IM. Endereço: FGV/EBAPE - Escola Brasileira de Administração Pública e de Empresas, Praia de Botafogo, 190 - $4^{\circ}$ e $5^{\circ}$ andares, Botafogo, CEP 22250-900, Rio de Janeiro - RJ, Brasil. E-mail: leonardo.darbilly@fgv.br

Doutoranda da EBAPE/FGV, sob orientação do Prof. Marcelo Milano F. Vieira até seu falecimento e integrante do grupo de pesquisa Observatório da Realidade Organizacional, núcleo Rio de Janeiro. Professora do Instituto Federal do Rio de Janeiro. Endereço: FGV/EBAPE - Escola Brasileira de Administração Pública e de Empresas, Praia de Botafogo, $190-4^{\circ}$ e $5^{\circ}$ andares, Botafogo, CEP 22250-900, Rio de Janeiro - RJ, Brasil. E-mail: diana.costa.de.castro@gmail.com 
nas dimensões material, estrutural e processual do espaço organizacional. Espaço este que, na visão de Marcelo Milano e, felizmente, também de alguns outros pensadores, é socialmente (re)construído.

Como sugere Martins (1999), esse 'espaço' pode ser definido em cinco dimensões: a já citada, física ou material - que compreende o universo das coisas (edifícios, equipamentos, ferramentas, materiais etc.) -, a tecnológica ou processual - representada pelas tecnologias (modus operandi) e os processos que o dinamizam -, a humana - que reúne as pessoas (atores) que atuam nesse locus e determinam o seu sentido e significados -, a dimensão política - resultante da necessidade de se estabelecer um sistema de poder/autoridade e de mediação e solução de conflitos - e, finalmente, a simbólica ou cultural - que estabelece os signos e os significados dos referentes desse universo, de sua dinâmica e das formas de relacionamento (interna e externa) de seus membros. A natureza desse sistema complexo e multidimensional e, em especial, de suas três últimas dimensões e sinergias, determinam um 'espaço' singular que se constrói e reconstrói historicamente.

Não obstante a inquestionável prevalência dessas três dimensões (humana, política e simbólica) na explicação de qualquer dinâmica social, os primeiros passos no sentido de resgatá-las na análise desse locus e de sua dinâmica foram dados somente a partir do final da terceira década do século passado, com o relato dos experimentos de Hawthorne (1927-32) por Elton Mayo (1945), nos Estados Unidos da América do Norte; a tradução para a língua inglesa, por Talcott Parsons e Henderson (WEBER 1947), da sociologia de Weber (1864-1920); e, bem mais tarde, com a corrente da Cultura Organizacional - "voga da Administração nos anos 80 [do século XX]", como propõe Freitas (1991, p. XVIII). Tais dimensões foram completamente olvidadas e/ou postas em segundo plano pelos trabalhos descritivos e funcionalistas dos teóricos pioneiros dos Estudos Organizacionais.

Como decorrência desse fato há, ainda hoje, um expressivo número de estudiosos da Administração (pública e privada) que sustentam a universalidade do fenômeno-objeto desse campo de estudo e que resistem à ideia de sua singularização, contestando, assim, as investidas teóricas no sentido de historicizá-lo e contextualizálo e de construir (entre nós) a disciplina Administração Brasileira. Herdeiros dessas teorizações mecanicistas pioneiras, esses estudiosos incorrem no reducionismo de refletir sobre um 'espaço' e uma dinâmica de natureza social utilizando epistemologias desenvolvidas para as ciências da natureza ou, dito de outra forma, supondo a universalidade das 'leis' que assim inferem.

Não se insere, entretanto, nessa corrente reducionista do pensamento administrativo contemporâneo, a contribuição de Marcelo Milano Falcão Vieira em sua passagem pela vida acadêmica nacional. Tendo produzido uma considerável quantidade de artigos divulgados em anais de congressos e em periódicos científicos nacionais e internacionais, além de um número significativo de livros e de sua atuação como coordenador do grupo de pesquisa Observatório da Realidade Organizacional, Núcleo Rio de Janeiro, podese destacar como uma das fortes características de seu pensamento organizacional a insatisfação que demonstrava com as abordagens tradicionais da teoria administrativa, ainda tão frequentes em trabalhos contemporâneos.

Não obstante o fato de sua produção ter apresentado mudanças ao longo do tempo, especialmente no tocante às perspectivas teóricas por ele utilizadas, como, por exemplo, a forte influência do pensamento estruturalista de Max Weber, passando pela utilização da perspectiva neoinstitucional proveniente da abordagem sociológica, à identificação com autores intérpretes do contexto brasileiro, tais como Celso Furtado, Guerreiro Ramos e Milton Santos, cabe frisar que a crítica ao pensamento administrativo e a preocupação com o desenvolvimento de uma teoria organizacional local esteve presente em grande parte de sua obra.

Nesse sentido, e em razão de tais preocupações, a aproximação com a disciplina Administração Brasileira, no âmbito da EBAPE/FGV, bem como o estudo do pensamento dos autores brasileiros ligados ao pensamento administrativo, sempre foi objeto de especial atenção por parte do professor Marcelo Milano. 
Essa característica também resultou na realização de atividades conjuntas do Observatório da Realidade Organizacional com o Programa de Estudos de Administração Brasileira, o que será detalhado mais adiante.

É importante destacar, ainda, a preocupação - constantemente expressa pelo professor Marcelo Milano a seus orientandos e alunos dos cursos de graduação, mestrado e doutoramento - com a ideia de que a Administração necessita estar alinhada à sociedade como um todo, uma vez que as organizações são produto de um determinado contexto social e sofrem influência constante do espaço em que estão inseridas. Sendo assim, a teoria administrativa é fruto das relações que os indivíduos estabelecem na prática, e devem, dessa forma, sempre retornar à sociedade, como em um movimento de observação, reflexão, abstração e ação. Se a abstração for tamanha a ponto de conseguir adequar-se a toda e qualquer sociedade, não servirá para retornar de maneira adequada a nenhuma sociedade, já que estará desfigurada; da mesma forma que uma teoria por demais detalhada e restrita a um único caso pouco se presta a formar um relevante corpus teórico.

Mais recentemente Marcelo Milano vinha adotando os estudos de geoestratégia, poder e gestão do espaço como uma de suas principais linhas de interesse de pesquisa, influenciado também pelo pensamento do professor Eurípedes Falcão Vieira, seu pai e pesquisador atuante, sobretudo na sua área de formação, a Geografia. Com base em tal interesse, o professor Marcelo Milano vinha orientando dissertações, teses, e pesquisas de iniciação científica as quais têm como referências teóricas os trabalhos de dois consagrados pensadores nacionais extremamente relevantes para a compreensão, direta ou tangencial, dos fenômenos que ocorrem nas organizações no nosso contexto: os professores Guerreiro Ramos e Milton Santos. Todos, infelizmente, deixaram esta vida sem que antes pudessem concluir suas teorias, mas nos legaram lúcidos suportes teóricos para a construção e reconstrução da disciplina Administração Brasileira.

\section{Marcelo Milano e o Programa de Estudos de Administração Brasileira}

O encontro de Marcelo Milano com o ABRAS deu-se em 2002, imediatamente após sua integração ao corpo docente permanente da EBAPE/FGV. O entusiasmo demonstrado por Marcelo pelos trabalhos de perspectiva histórica do ABRAS e, consequentemente, de utilização do pensamento social brasileiro e dos intérpretes de nossa nacionalidade como epistemologia, metodologia e referências nos estudos organizacionais, revelou-se logo no primeiro contato com as atividades acadêmicas desse programa e com os seus pesquisadores.

Em 2005, Marcelo Milano co-organizou com Deborah Moraes Zouain o livro Pesquisa Qualitativa em Administração: Teoria e prática, publicado pela Editora FGV. O professor Paulo Emílio Matos Martins, criador e coordenador do ABRAS e signatário destas notas, foi convidado para participar dessa coletânea de textos. Seu artigo, Administração Brasileira: uma disciplina em construção (2005), foi escolhido pelos organizadores do livro para abrir a obra. Assim, Marcelo demonstrava o seu reconhecimento pelo trabalho que o ABRAS vinha realizando já há mais de duas décadas.

No ano seguinte, o professor Marcelo Milano, como organizador do IV Encontro de Estudos Organizacionais (EnEO), promovido pela Associação Nacional de Ensino e Pesquisa em Administração (ANPAD), propôs a concessão da distinção Trabalho de Destaque do Encontro para o artigo O poder do bacharel no espaço organizacional brasileiro: Relendo raízes do Brasil e sobrados e mucambos, de autoria dos pesquisadores do ABRAS, Breno de Paula Andrade Cruz e Paulo Emílio Martins (2006).

Como pesquisador do projeto Cultura, Mercado e Desenvolvimento (EBAPE/FGV - CPGA/UFSC), financiado pelo Procad/Capes, Marcelo Milano convidou o criador do ABRAS para ministrar a disciplina Administração Brasileira, no segundo semestre de 2008, no curso de Pós-Graduação (stricto sensu) em Administração da Universidade Federal de Santa Catarina (CPGA/UFSC). Esta foi a primeira vez que esse tema foi oferecido em um seminário de pós-graduação fora das IESs onde surgiu - Universidade Federal Fluminense e EBAPE/FGV. 
Ainda nesse mesmo ano de 2008, Marcelo Milano participou, como convidado do ABRAS (organizador do evento), do simpósio O Brasil em Evidência: A Utopia do Desenvolvimento, coordenando a mesa Celso Furtado e o Mito do Desenvolvimento Econômico. O texto com a fala de Marcelo no evento está sendo publicado em coletânea com os trabalhos discutidos nesse simpósio que celebrou o centenário de nascimento de Josué de Castro e analisou o pensamento social brasileiro do seu tempo (anos 50 a 70 do século passado).

Mais tarde, como líder do grupo de pesquisadores do Observatório da Realidade Organizacional na EBAPE/FGV, Marcelo Milano foi convidado a participar do projeto Contribuições do Pensamento Social Brasileiro para a Qualificação do Ensino e da Pesquisa em Administração Pública (2009-2013), coordenado pelo ABRAS, financiado pelo Programa de Apoio ao Ensino e à Pesquisa Científica em Administração (PROAD), da CAPES, e conduzido, conjuntamente, pelos seguintes programas: ABRAS/EBAPE/FGV, PPGA/UFRGS e PPGAd/UFF. Para a I Oficina desse projeto, que discutiu O Conhecimento sobre Administração Pública: em Busca do Pensamento Brasileiro, o professor Marcelo Milano organizou e coordenou a atividade A Pesquisa em Arquivos e a História Oral, realizada na cidade do Rio de Janeiro em 9 de junho de 2010. Em 29 de setembro de 2010, participou, em Niterói, como conferencista-convidado, da II Oficina daquele projeto, promovida e realizada pelo Departamento de Administração da Faculdade de Administração, Ciências Contábeis e Turismo da UFF e que teve como tema-guia: Conteúdos e Práticas para a Formação do Administrador Público.

Ainda de 2010 é contribuição de Marcelo Milano para o I Encontro Nacional: Pensamento Social Brasileiro e Administração Pública, do projeto PROAD/CAPES, organizado, conjuntamente, pelo ABRAS (EBAPE/FGV); Observatório da Realidade Organizacional (EBAPE/FGV); Programa de Pós-Graduação em Administração (Escola de Administração/UFRGS); e Faculdade de Administração, Ciências Contábeis e Turismo (UFF) - realizado na cidade do Rio de Janeiro de 8 a 9 de dezembro de 2010. Como organizador da Mesa Espaço e Território no Pensamento de Milton Santos, Marcelo Milano coordenou os trabalhos que discutiram a rica contribuição daquele autor e seu pensamento social.

Malgrado o seu precoce falecimento, é bastante significativa a contribuição que o professor Marcelo Milano deixa como legado a esse Projeto nos seus dois primeiros anos de desenvolvimento. Infelizmente, no ano recém-findo, 2011, o ABRAS e o Projeto PROAD/CAPES não mais puderam contar com o talento e o entusiasmo de Milano na construção de uma visão singular e histórica do 'espaço' organizacional brasileiro. O penoso tratamento médico a que se submeteu e o precoce desaparecimento do saudoso colega privaramnos de uma fecunda contribuição.

\section{Algumas Notas sobre o Pensamento de Marcelo Milano e os Intérpretes do Brasil}

Mesmo conturbado e frequentemente interrompido pelo tratamento médico, seus últimos anos de vida foram profícuos em termos de repensar teorias e posicionamentos. Marcelo Milano não poupou esforços para discutir temas que tanto vinham agradando seu pensar acadêmico e que ele percebia como essenciais para o estudo das organizações. Seu interesse pela relação existente entre o espaço ou território e a atuação das organizações acabou por se tornar seu principal foco de atenção nos últimos tempos. Sob sua coordenação, seus orientandos engajaram-se na leitura das principais obras de Milton Santos, de alguns trabalhos desenvolvidos por outros núcleos do grupo de pesquisa Observatório da Realidade Organizacional e, ainda, de Geoestratégia Global (2007), livro de autoria dele e do professor Eurípedes Falcão Vieira.

Os encontros para discutir essas leituras eram realizados semanalmente na sala 530 do prédio da EBAPE/FGV, sendo, em alguns casos, uma continuação de conversas realizadas em salas de aula durante as diversas disciplinas que lecionava na Escola, tais como, Pensamento Organizacional e Análise de Dados Qualitativos, apenas para citar algumas pelas quais foi responsável nos últimos dois anos. Entretanto, na maioria das vezes, as reuniões semanais realizadas pelo professor Marcelo e seus orientandos tinham como 
intuito auxiliá-los na construção e desenvolvimento de seus trabalhos de pesquisa, em paralelo, ainda, aos encontros de orientação que regularmente ocorriam e que geralmente vinham acompanhados de ricas contribuições por parte do professor Marcelo, fruto de uma sempre detalhada e cuidadosa leitura que ele fazia dos trabalhos de seus orientandos.

Ainda no que tange ao seu interesse mais recente pelo pensamento de Milton Santos, é importante mencionar que, ao longo de tais encontros e reuniões, percebeu-se que o conceito de espaço sofreu modificações tanto nas obras do autor quanto em outras que o tinham como principal referência. Era, portanto, um desafio necessário trabalhar com esse conceito em mutação e, ao mesmo tempo, evidente que, para o professor Marcelo, tal conceito precisava de um amadurecimento suficiente para auxiliar os estudiosos das organizações.

Tendo atuado em toda sua trajetória acadêmica na área de Estudos Organizacionais, ultimamente vinha interessando-se especialmente em compreender de que maneira as organizações modificam a dinâmica de um determinado espaço e também como as relações de poder e de forças presentes nesse espaço acabam por influenciar ou modificar a própria atuação das organizações nele constituídas. As relações existentes entre as organizações e a sociedade se faziam de grande interesse dentro de tais estudos, sobretudo a partir de uma visão crítica de como essas organizações modificam e transformam o espaço. ${ }^{4}$ Nesse último caso, as perspectivas de Milton Santos estavam sendo aliadas às leituras de Paulo Freire sobre emancipação com foco na ação social, privilegiando novamente uma leitura feita por autores brasileiros.

Assim, o interesse por entender de que maneira a dinâmica das organizações influencia um determinado espaço ou território e vice-versa vinha sempre acompanhado de uma consideração de elementos que o professor Marcelo tinha como essenciais para uma adequada compreensão sobre a atuação das organizações, em especial a questão do poder, fenômeno este que, aliás, já era por ele estudado desde há muito tempo, especialmente com base em autores pertencentes ao estruturalismo francês, como o sociólogo Pierre Bourdieu. $^{5}$

Ainda, é importante mencionar que, sendo bastante crítico à utilização da noção de ambiente na análise organizacional, por ser proveniente de uma perspectiva sistêmico-funcionalista, a qual tende a considerar os conflitos e disputas de poder como algo que torna o sistema organizacional disfuncional, o professor Marcelo vinha refletindo junto com seus orientandos a respeito de se utilizar o conceito de espaço, conforme desenvolvido por Milton Santos, como uma possibilidade de se escapar de tal limitação. O que, em sua visão, poderia ser frutífero na área de estudos organizacionais exatamente pelo fato de levar em conta as disputas de poder, as relações de forças e os conflitos que ocorrem em um determinado espaço e que modificam ou influenciam a atuação das organizações. Tal ideia, ainda em fase de amadurecimento, não chegou a ser expressa por meio de publicação em congressos ou periódicos, mas estava sendo abraçada com entusiasmo por seus orientandos.

\section{Um exemplo de luta e um sentimento de saudade}

Como legatários do talento e do exemplo de tenacidade e luta do professor Marcelo Milano Falcão Vieira e de seu pensamento sobre as organizações, nós, seus colegas do ABRAS e do projeto Proad/Capes,

${ }^{4}$ Ver o trabalho de Costa et al. (2011) produzido sob orientação do Prof. Marcelo Milano. Outros trabalhos ainda estão sem publicação, como as dissertações de Diana Castro e Cristiane Simões Costa.

${ }^{5}$ Um exemplo de trabalho cujo foco esteve nas relações de poder no campo do mercado fonográfico, por meio da perspectiva de Pierre Bourdieu, e que se constituiu em fruto de trabalho de orientação do professor Marcelo Milano foi An analysis of the recorded music industry field in Brazil. Asia Pacific Journal of Arts and Cultural Management (DARBILLY e VIEIRA, 2010). 
registramos o nosso profundo pesar pela sua perda e a certeza de que seguiremos pelejando na construção de um conhecimento administrativo, não xenófobo, porém autônomo, e comprometido com a nossa realidade histórica e a construção de uma sociedade mais justa e digna para todos os brasileiros.

\section{Referências}

COSTA, C. S. N. et al. Política cultural e desenvolvimento: uma análise do Programa Bairro Escola, do município de Nova Iguaçu - Rio de Janeiro. Cad. EBAPE.BR, v. 9, n. 4, dez. 2011. Disponível em: http://www.ebape.fgv.br/cadernosebape. Acesso em: 02 fev. 2012.

CRUZ, B. P. A.; MARTINS, P. E. M. O poder do bacharel no espaço organizacional brasileiro: Relendo raízes do Brasil e sobrados e mucambos. In: Cad. EBAPE.BR, v. 9, n. 3, out. 2006. Disponível em: www.ebape.fgv.br/cadernosebape. Acesso em: 29 jan. 2012.

DARBILLY, L. V. C.; VIEIRA, M. M. F. An analysis of the recorded music industry field in Brazil. Asia Pacific Journal of Arts and Cultural Management, v. 7, n. 1, jul. p. 528-539, 2010.

FAYOL, H. Administração Industrial e Geral. São Paulo: Editora Atlas, 1950.

FREITAS, M. E. de. Cultura organizacional: Formação, tipologias e impactos. São Paulo: Makron, Mc-Graw-Hill, 1991.

MARTINS, P. E. M. A reinvenção do sertão: A estratégia organizacional de Canudos. Rio de Janeiro: Editora FGV, 1999.

Administração Brasileira: Uma disciplina em construção. In: VIEIRA, M.; ZOUAIN, D. (Orgs.). Pesquisa Qualitativa em Administração. Vol. II. Rio de Janeiro: Editora FGV, Rio de Janeiro, 2005, pp.11-28.

MAYO, E. The Social Problems of an Industrial Civilization. Cambridge, Mass.: Havard University Press, 1945.

TAYLOR, F. W. Princípios de Administração Científica. São Paulo: Editora Atlas, 1970.

VIEIRAL, M. M. F.; VIEIRA, E. F. Geoestratégia global: Economia, poder e gestão do território. 1. ed. v.1. Rio de Janeiro: FGV Editora, 2007.

WEBER, M. The Theory of Social and Economic Organization. Trad. de A. M. Henderson e Talcott Parsons. New York: Oxford University Press, 1947. 